\title{
Avaliação das estruturas organizacionais dos organismos gestores da mobilidade diante da Política Nacional de Mobilidade Urbana
}

Assessment of the organizational structures of mobility management authorities in view of the National Urban Mobility Policy

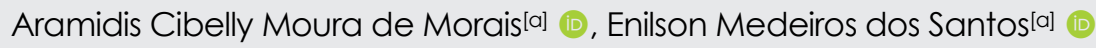

[a] Universidade Federal do Rio Grande do Norte (UFRN), Natal, RN, Brasil

Como citar: Morais, A. C. M., \& Santos, E. M. (2020). Avaliação das estruturas organizacionais dos organismos gestores da mobilidade diante da Política Nacional de Mobilidade Urbana. urbe. Revista Brasileira de Gestão Urbana, 12, e20190232. https://doi.org/10.1590/2175-3369.012.e20190232

\section{Resumo}

O objetivo desta pesquisa é avaliar criticamente a funcionalidade da estrutura organizacional de um órgão gestor de mobilidade diante da problemática nesse setor e dos requerimentos prescritos pela Política Nacional de Mobilidade Urbana (Lei no 12.587/2012). A problemática da mobilidade urbana nas cidades brasileiras motivou a criação dessa política, cuja efetivação é um fator de aprimoramento das condições da vida urbana no país. Assim, é necessária a adequação da estrutura organizacional dos organismos gestores nas cidades. Como método de pesquisa, foi utilizada uma matriz de avaliação elaborada com base na revisão de literatura de O\&M (organização e métodos) e nos requisitos da Lei $\mathrm{n}$ - $12.587 / 2012$. A coleta de informações sobre o organismo avaliado foi realizada por meio de pesquisa documental e entrevistas semiestruturadas com gestores e stakeholders do setor. A pesquisa foi aplicada no órgão gestor de transportes da Região Metropolitana de Recife (RMR). A análise crítica dos resultados permitiu concluir que a estrutura organizacional do órgão gestor não está totalmente adequada aos requerimentos da Política Nacional de Mobilidade Urbana e configura uma situação em que são necessárias mudanças para a sua completa adequação.

Palavras-chave: Mobilidade urbana. Política Nacional de Mobilidade Urbana. Organismos gestores. Estrutura organizacional.

\begin{abstract}
The objective of this work is to evaluate critically the functionality of the organizational structure of mobility authorities' managers in the face of problems in this sector and the requirements prescribed by the National Policy on Urban Mobility (Law no 12.587/2012). The issue of urban mobility in Brazilian cities motivated the creation of this policy, whose effectiveness is a factor of improvement of the conditions of urban life in the country. For this, it is necessary to adapt the organizational structure of the managing organisms in the cities. As a research method, an evaluation matrix was elaborated based on O\&M (Organization and methods) literature review and the requirements of Federal Law number 12.587/2012. The collection of information about the evaluated organism was carried put through a documental
\end{abstract}

ACMM é bacharel em Administração, mestre em Engenharia de Produção, e-mail: aramidiscibelly@hotmail.com

EMS é engenheiro civil, doutor em Engenharia de Transportes, e-mail: enilson@supercabo.com.br 
research and semi-structured interviews with managers and stakeholders of the sector. The research was applied in the transport management body of the Metropolitan Region of Recife (RMR), which is a public consortium in development. The critical analysis of the results allowed concluding that the organizational structure of the managing authorities is not totally adequate to the requirements of the National Policy and configures a situation in which changes are necessary for its complete adequacy.

Keywords: Urban mobility. National Policy on Urban Mobility. Management authorities. Organizational structure.

\section{Introdução}

As cidades brasileiras vivenciam a problemática da mobilidade urbana, que se desenvolveu ao longo de anos de crescimento urbano acelerado sem planejamento adequado nesse setor. São efeitos dessa problemática nas regiões metropolitanas: o modelo de deslocamentos centrado nos automóveis, que beneficiam apenas uma parcela da população, mas cujos custos e efeitos negativos (acidentes e poluição atmosférica) são socializados; e a falta de priorização do transporte coletivo na via, o qual disputa espaço com os carros, ficando preso nos congestionamentos (Boareto, 2003), aumentando o tempo de deslocamento e, consequentemente, ocasionando a perda da demanda cativa que adere ao transporte individual (Brasil, 2015).

A Constituição Federal de 1988 foi o marco inicial para a política de mobilidade urbana no Brasil (Brasil, 1988). A Carta Magna colocou como competência da União "[...] instituir diretrizes para o desenvolvimento urbano, inclusive habitação, saneamento básico e transportes urbanos" (Art. 21, inciso XX), assim como declarou ser de competência exclusiva dela legislar sobre as diretrizes da Política Nacional de Transportes (Art. 22, inciso IX).

Entretanto, apenas 24 anos após a promulgação da Constituição é que foi formalmente estabelecida pela Lei no 12.587/2012 a Política Nacional de Mobilidade Urbana (PNMU). Essa lei de âmbito nacional estabelece os princípios, os objetivos e as diretrizes da PNMU, os quais deverão estar presentes no Plano de Mobilidade Urbana (Plamob), que é o instrumento de efetivação da política em nível local.

A Constituição de 1988 concedeu autonomia aos municípios e, na área de transporte urbano, determinou a essa esfera de poder a competência pela gestão e operação dos serviços locais de transporte público. Para os transportes intermunicipais de passageiros, a competência pela gestão foi dada aos Estados. Porém, nas regiões metropolitanas, a responsabilidade pelo transporte público não foi delegada a nenhum ente político, visto que não se trata de esfera de governo. Há dispositivo constitucional para que os municípios e o Estado constituam consórcios públicos para a gestão e operação de serviços de interesse comum, regulamentada pela Lei Federal no 11.107/2005 - Lei de Consórcios Públicos -, entretanto não é uma medida de caráter obrigatório.

Em nível organizacional, a mobilidade urbana é um assunto complexo por envolver variadas instituições - governamentais, operadores privados e organizações da sociedade civil. Além disso, envolve diversos tipos de serviço - transportes coletivos, transportes não motorizados, infraestrutura dos modos de transportes, passeio público e serviços de informação -, que torna a sua complexidade ainda superior. Isso favorece para que haja fragmentação na gestão da mobilidade urbana, sobretudo em regiões metropolitanas, dificultando a eficácia e a efetividade desses serviços. Diante disso, é questionado se os organismos locais e metropolitanos de transporte urbano estão ajustados a dar respostas aos requerimentos de gestão estabelecidos pela PNMU.

O objetivo desta pesquisa é avaliar criticamente a funcionalidade da estrutura organizacional de um organismo gestor da mobilidade diante da problemática nesse setor e dos requerimentos prescritos pela Política Nacional de Mobilidade Urbana (Lei no 12.587/2012). Para isso, foi desenvolvida uma matriz de avaliação de estruturas organizacionais para esses órgãos, considerando os conhecimentos de organização e métodos e as disposições da Lei no $12.587 / 2012$. 0 caso de aplicação nesta pesquisa foi o órgão gestor na Região Metropolitana de Recife, Pernambuco, Brasil. A matriz foi desenvolvida dada a ausência de um método específico para atender ao objetivo desta pesquisa e pode ser aplicada também em outros casos. 
A pesquisa justifica-se pelas reais necessidades de organização dos sistemas de mobilidade urbana nas cidades e regiões metropolitanas e, assim, pela efetivação da PNMU, dada sua importância ao fato de a mobilidade urbana ser uma função pública do Estado, o qual deve garantir acessibilidade a todos e disponibilizar atendimento adequado às diferentes necessidades de deslocamentos (Boareto, 2003). 0 transporte promove o acesso ao emprego, habitação, educação, saúde, lazer, mercados e outras oportunidades que são essenciais para a qualidade de vida nas áreas urbanas. Também favorece o crescimento econômico da comunidade e das empresas.

\section{Construção de uma Política Nacional de Mobilidade Urbana no Brasil}

A Constituição Federal de 1988 foi a primeira a mencionar uma política nacional de transporte urbano e a tratar sobre a política de desenvolvimento urbano (Brasil, 1988). Segundo o texto constitucional, a política de desenvolvimento urbano "[...] tem por objetivo ordenar o pleno desenvolvimento das funções sociais da cidade e garantir o bem-estar de seus habitantes". É função do Poder Público Municipal executá-la conforme diretrizes fixadas em lei formal (Art. 182). A própria Constituição já havia colocado a necessidade de uma lei para estabelecer e regulamentar a política nacional de desenvolvimento urbano. No entanto, essa lei só foi promulgada em 10 de julho de 2001 - Lei Federal № 10.257 -, denominada Estatuto da Cidade.

O Estatuto da Cidade visa concretizar o "direito à cidade", definido como "[...] o direito à terra urbana, à moradia, ao saneamento ambiental, à infraestrutura urbana, ao transporte e aos serviços públicos, ao trabalho e ao lazer, para as presentes e futuras gerações" (Brasil, 2001). A lei foi promulgada após mais de dez anos de um intenso processo de negociação entre forças políticas e sociais (Fernandes, 2010; Bassul, 2002). No que remete ao transporte urbano, o Estatuto da Cidade determinou o desenvolvimento de Planos Diretores de Transporte Urbano para os municípios com população acima de 500 mil habitantes (Brasil, 2001). Entretanto, não houve uma definição clara ou mínima de seu conteúdo. Em 2005, a Resolução no 34 do Conselho das Cidades definiu o escopo mínimo para um Plano Diretor de Mobilidade e Transportes (Lima \& Galindo, 2013).

A mobilidade urbana começou a ter importância na legislação brasileira, mas o principal marco regulatório desse setor foi a Lei Federal no 12.587, promulgada em 3 de janeiro de 2012, que oficializou a Política Nacional de Mobilidade Urbana (PNMU). Foi aprovada a partir do Projeto de Lei no 1.687/2007, originado do PL no 694/1995, que reunia alguns projetos de lei anteriores sobre transporte coletivo.

Embora tenha sido formalizada por lei em 2012, a PNMU já havia sido elaborada pelo Ministério das Cidades desde 2004, publicada em um caderno institucional que foi a base para a elaboração do PL no 1.687/2007. Esse projeto de lei foi conduzido pelo Poder Executivo, e seu processo de elaboração foi amplamente democrático, contando com a participação de atores políticos, do setor de transportes e da sociedade civil organizada, além de ouvir a opinião da população por meio de um portal eletrônico (Gomide, 2007).

O PL no $1.687 / 2007$ discutia uma proposta para a mobilidade urbana com uma abordagem mais abrangente sobre o tema dos PLs anteriores, que levavam em conta apenas o transporte coletivo. Além de considerar os modos não motorizados na cidade, no aspecto institucional previa regras claras com determinações adequadas em vez da discricionariedade de políticos, sendo isso essencial para consolidar a política (Gomide, 2007). Como desvantagem, assim como o PL no 694/1995, não havia a previsão de um programa com fonte de recursos para o setor (Lima \& Galindo, 2013).

A motivação para a proposta desse projeto de lei decorre do diagnóstico realizado pela Secretária de Mobilidade Urbana do Ministério das Cidades a respeito do modelo de mobilidade urbana nas cidades brasileiras, o qual indicava que tal modelo caminhava para a insustentabilidade por causa da: 
Baixa prioridade dada a oferta do transporte coletivo; [das] externalidades negativas causadas pelo uso intensivo dos automóveis (congestionamento e poluição do ar); [da] carência de investimentos públicos e fontes de financiamento ao setor; [da] fragilidade da gestão pública nos municípios; e [da] necessidade de políticas públicas articuladas nacionalmente (IPEA, 2012, p. 2).

Também foram determinantes as manifestações dos estudantes em algumas cidades no ano de 2003 contra o aumento das tarifas de ônibus, que chamaram a atenção dos prefeitos para discutir sobre a "[...] desoneração dos custos do transporte urbano" (Gomide, 2007). Era necessária a formulação da política pública nacional para o setor de transporte urbano, o que veio a ser promulgada em 2012, após cinco anos de tramitação do PL no $1.687 / 2007$.

Segundo a Lei no $12.587 / 2012$, a PNMU tem por objetivo:

Contribuir para o acesso universal à cidade, o fomento e a concretização das condições que contribuam para a efetivação dos princípios, objetivos e diretrizes da política de desenvolvimento urbano, por meio do planejamento e da gestão democrática do Sistema Nacional de Mobilidade Urbana (Brasil, 2012).

O conceito de mobilidade urbana é ressaltado na lei como "[...] a condição em que se realizam os deslocamentos de pessoas e cargas no espaço urbano" (Brasil, 2012). Nos Artigos 5, 6 e 7, são definidos os princípios, as diretrizes e os objetivos da PNMU (Tabela 1).

Tabela 1 - Princípios, diretrizes e objetivos da PNMU

Acessibilidade universal.

Desenvolvimento sustentável das cidades.

Equidade no acesso dos cidadãos ao transporte público coletivo (TPC).

$\frac{.0}{\frac{0}{0}}$

Eficiência, eficácia e efetividade na prestação dos serviços de transporte urbano.

Gestão democrática e controle social do planejamento e avaliação da PNMU.

Segurança nos deslocamentos das pessoas.

Justa distribuição dos benefícios e ônus decorrentes do uso dos modos e serviços.

Equidade no uso do espaço público de circulação, vias e logradouros.

Eficiência, eficácia e efetividade na circulação urbana.

Integração com a política de desenvolvimento urbano e as políticas setoriais no âmbito dos entes federativos.

Prioridade dos modos de transportes não motorizados sobre os motorizados e dos serviços de TPC sobre o transporte individual motorizado.

Integração entre os modos e serviços de transporte urbano.

产

Mitigação dos custos ambientais, sociais e econômicos dos deslocamentos de pessoas e cargas na cidade.

Incentivo ao desenvolvimento científico-tecnológico e ao uso de energias renováveis e menos polventes.

Priorização de projetos de transporte público coletivo estruturadores do território e indutores do desenvolvimento urbano integrado.

Integração entre as cidades gêmeas localizadas na faixa de fronteira com outros países sobre a linha divisória internacional.

Reduzir as desigualdades e promover a inclusão social.

Promover o acesso aos serviços básicos e equipamentos sociais.

$\frac{20}{\frac{2}{0}}$

Proporcionar melhoria nas condições urbanas da população no que se refere à acessibilidade e à mobilidade.

Promover o desenvolvimento sustentável com a mitigação dos custos ambientais e socioeconômicos dos deslocamentos de pessoas e cargas nas cidades.

Consolidar a gestão democrática como instrumento e garantia da construção contínua do aprimoramento da mobilidade urbana.

Fonte: Brasil (2012). 
A Lei no 12.587/2012 determina as atribuições dos entes federativos (União, Estados e municípios) na gestão da mobilidade urbana. Aos municípios compete planejar, executar e avaliar a política de mobilidade urbana; regulamentar a prestação dos serviços de transporte urbano; prestar, direta ou indiretamente ou por gestão associada, os serviços de transporte público coletivo urbano; capacitar pessoas; e desenvolver as instituições vinculadas à política de mobilidade urbana do município (Brasil, 2012).

Em áreas metropolitanas, a organização e a prestação dos serviços de transporte coletivo intermunicipal de caráter urbano são de responsabilidade dos Estados, mas podem ser delegadas aos municípios, se constituído consórcio público ou convênio de cooperação para essa finalidade. Também são pontos relevantes dispostos na lei as determinações para o processo de delegação dos serviços de transporte coletivo, bem como da política tarifária para esse modo (Brasil, 2012).

0 instrumento de efetivação da PNMU nas cidades é o Plano de Mobilidade Urbana (Plamob), que deve ser integrado e compatível com o Plano Diretor Municipal (PDM) ou nele inserido (Brasil, 2012). A elaboração desse instrumento é obrigatória para todos os municípios acima de 20 mil habitantes, diferentemente do que propôs o Estatuto da Cidade. Em 2012, o número total de municípios que deveriam elaborar o Plamob era de 3.065 (IBGE, 2012).

Embora haja avanços no reconhecimento do tema da mobilidade urbana por parte do Poder Público Federal, há fragilidades nessa política que comprometem a sua efetividade. A lei não expressa a tipologia do Plamob, se ele deve ser apresentado em forma de lei municipal, a exemplo do PDM, ou por meio de um documento de referência de política pública. Isso pode resultar em perda de efetividade, por não haver um guia nem a obrigatoriedade para o Poder Público Municipal executar a lei (Lima \& Galindo, 2013).

Quando promulgada em 2012, a Lei no 12.587 determinou que os municípios deveriam elaborar o Plamob no prazo máximo de três anos a partir da data de vigência da lei, mas foi revogado em 2016 pela Lei no 13.406 para seis anos e, em 2018, para sete anos pela Medida Provisória no 818. A penalidade para os municípios que descumprirem essa exigência é o impedimento de receber recursos orçamentários federais destinados à mobilidade urbana até que atendam à condição (Art. 24, § 4ํㅜ) (Brasil, 2012).

\section{Metodologia para avaliação da estrutura organizacional de organismos gestores da mobilidade urbana}

0 método de pesquisa consistiu em aplicar uma matriz de avaliação específica para avaliar a funcionalidade das estruturas organizacionais de organismos gestores da mobilidade urbana nas cidades brasileiras diante das disposições da Lei Federal no 12.587/2012. O método foi elaborado a partir da análise da literatura sobre organização e métodos (O\&M) e do texto dessa lei, visando elencar requisitos necessários a um órgão de transporte urbano capaz de implementar a Política Nacional de Mobilidade Urbana (PNMU).

Durante a pesquisa bibliográfica, não foi encontrado nenhum trabalho acadêmico que se debruçasse efetivamente sobre a gestão dos organismos da mobilidade urbana nas cidades brasileiras em relação a essa política de Estado. Logo, foi necessário elaborar um método de pesquisa que pudesse alcançar o objetivo proposto.

A matriz de avaliação sistematiza e ordena um rol de variáveis ou critérios a serem observadas no trabalho empírico, que forneça uma avaliação formal das potencialidades do caso estudado em responder adequadamente aos ditames da PNMU. Fundamenta-se no agrupamento dessas variáveis (Tabela 2) de maneira a facilitar a análise das informações coletadas e possibilitar resultados consistentes para a pesquisa. A Tabela 2 apresenta os critérios avaliados na matriz e suas respectivas explicações. 
Tabela 2 - Critérios da matriz de avaliação

Critérios elencados na matriz de avaliação

\begin{tabular}{|c|c|c|c|}
\hline \multicolumn{2}{|c|}{ Critérios da Lei $n^{\circ} 12.587 / 2012$} & \multicolumn{2}{|c|}{ Critérios da literatura de O\&M } \\
\hline $\begin{array}{l}\text { Gerência dos modos } \\
\text { de transporte urbano }\end{array}$ & $\begin{array}{c}\text { Inclusão de todos os modos motorizados e não } \\
\text { motorizados que circulam na cidade. Quanto } \\
\text { ao objeto, de passageiro e de cargas; quanto } \\
\text { às características do serviço, coletivo e } \\
\text { individual; quanto à natureza do serviço, público } \\
\text { e privado (Art. 3). }\end{array}$ & $\begin{array}{l}\text { Histórico da } \\
\text { organização }\end{array}$ & $\begin{array}{l}\text { Alteração na estrutura } \\
\text { da organização, idade } \\
\text { e corpo técnico. }\end{array}$ \\
\hline $\begin{array}{l}\text { Infraestrutura de } \\
\text { mobilidade urbana }\end{array}$ & $\begin{array}{l}\text { Vias e demais logradouros públicos } \\
\text { (metroferrovias, hidrovias e ciclovias), } \\
\text { estacionamentos, terminais, estações e } \\
\text { demais conexões, pontos para embarque e } \\
\text { desembarque de passageiros e cargas, } \\
\text { sinalização viária e de trânsito, equipamentos } \\
\text { e instalações, instrumentos de controle, } \\
\text { fiscalização, arrecadação de taxas e tarifas e } \\
\text { difusão de informações (Art. 3, § 3). }\end{array}$ & $\begin{array}{l}\text { Atividades, } \\
\text { autoridade e } \\
\text { comunicação }\end{array}$ & $\begin{array}{l}\text { Divisão e organização } \\
\text { do trabalho; } \\
\text { disseminação da } \\
\text { autoridade; sistema de } \\
\text { comunicação para } \\
\text { coordenar as atividades, } \\
\text { os processos e as áreas. }\end{array}$ \\
\hline $\begin{array}{l}\text { Medidas de } \\
\text { sustentabilidade } \\
\text { ambiental }\end{array}$ & $\begin{array}{c}\text { Medidas mitigadoras de custos ambientais, } \\
\text { como controle de emissão de polventes e } \\
\text { incentivos ao transporte coletivo e não } \\
\text { motorizado (Art. } 23 \text { ). }\end{array}$ & Formalização & $\begin{array}{l}\text { Existência de manuais } \\
\text { escritos e regulamentos } \\
\text { da organização. }\end{array}$ \\
\hline Acessibilidade & $\begin{array}{c}\text { Acesso físico às infraestruturas e aos modos } \\
\text { de transporte (Art. 14). }\end{array}$ & $\begin{array}{l}\text { Centralização e } \\
\text { descentralização }\end{array}$ & $\begin{array}{l}\text { Centros de decisão e } \\
\text { delegação na estrutura } \\
\text { organizacional. }\end{array}$ \\
\hline $\begin{array}{l}\text { Elementos de gestão } \\
\text { participativa }\end{array}$ & $\begin{array}{l}\text { Órgãos colegiados com representantes do } \\
\text { Poder Executivo, da sociedade civil e dos } \\
\text { operadores dos serviços; ouvidorias nos } \\
\text { órgãos de gestão da mobilidade urbana; } \\
\text { audiências e consultas públicas (Art. 15). }\end{array}$ & $\begin{array}{l}\text { Estratégias, políticas e } \\
\text { objetivos } \\
\text { organizacionais }\end{array}$ & $\begin{array}{l}\text { Elementos } \\
\text { organizacionais } \\
\text { definidos em um } \\
\text { planejamento } \\
\text { estratégico (PE) } \\
\text { formalizado. }\end{array}$ \\
\hline $\begin{array}{l}\text { Comunicação e } \\
\text { informação ao } \\
\text { usuário }\end{array}$ & $\begin{array}{l}\text { Canais de atendimento ao usuário e de } \\
\text { disponibilidade de informações sobre o } \\
\text { sistema de mobilidade urbana (Art. 14, 15). }\end{array}$ & Tecnologia & $\begin{array}{c}\text { Tecnologia da } \\
\text { informação e } \\
\text { comunicação (TICs) na } \\
\text { organização e para o } \\
\text { sistema de mobilidade } \\
\text { urbana. } \\
\end{array}$ \\
\hline $\begin{array}{l}\text { Informaçōes do } \\
\text { transporte coletivo }\end{array}$ & $\begin{array}{l}\text { Informação ao usuário sobre tarifas, pontos } \\
\text { de embarque e desembarque, horários e } \\
\text { integração com outros modos (Art. 14, III). }\end{array}$ & $\begin{array}{l}\text { Ambiente } \\
\text { organizacional }\end{array}$ & $\begin{array}{c}\text { Interno (unidades } \\
\text { organizacionais) e } \\
\text { externo (agentes } \\
\text { envolvidos na questão } \\
\text { da mobilidade urbana } \\
\text { na região). } \\
\end{array}$ \\
\hline $\begin{array}{l}\text { Transparência e } \\
\text { simplicidade na tarifa }\end{array}$ & $\begin{array}{c}\text { Simplicidade na compreensão, } \\
\text { transparência da estrutura tarifária para o } \\
\text { usuário e publicidade do processo de } \\
\text { revisão (Art. } 8, \mathrm{~V} \text { ). }\end{array}$ & & \\
\hline $\begin{array}{l}\text { Integração com as } \\
\text { políticas setoriais } \\
\text { urbanas }\end{array}$ & $\begin{array}{c}\text { Integração com políticas de } \\
\text { desenvolvimento urbano, tais como uso e } \\
\text { ocupação do solo, saneamento ambiental } \\
\text { e habitação (Art. } 6,1) \text {. }\end{array}$ & & \\
\hline $\begin{array}{l}\text { Plano de Mobilidade } \\
\text { Urbana }\end{array}$ & $\begin{array}{c}\text { Instrumento de efetivação da PNMU que } \\
\text { deve contemplar os princípios, os objetivos e } \\
\text { as diretrizes presentes na Lei n } 12.587 / 2012 \\
\text { (Art. 24). }\end{array}$ & & \\
\hline Gestão de trânsito & Infraestruturas de transportes (Art. 3, § 3). & & \\
\hline $\begin{array}{l}\text { Capacitação de } \\
\text { pessoas em } \\
\text { mobilidade urbana }\end{array}$ & $\begin{array}{c}\text { Capacitação continuada de pessoas em } \\
\text { mobilidade urbana (Art. 16, II). }\end{array}$ & & \\
\hline $\begin{array}{l}\text { Avaliação de } \\
\text { desempenho nos } \\
\text { serviços }\end{array}$ & $\begin{array}{l}\text { Avaliação e fiscalização dos senviços e } \\
\text { monitoramento dos desempenhos, } \\
\text { garantindo a consecução das metas de } \\
\text { universalização e de qualidade (Art. 22, II). }\end{array}$ & & \\
\hline
\end{tabular}

Fonte: Elaborada pelos autores (2016). 
A pesquisa foi desenvolvida nas seguintes etapas:

1. Análise teórica e estruturação da matriz de avaliação: a literatura de O\&M foi retratada como referencial para a estruturação do método e avaliação da estrutura organizacional do ponto de vista administrativo. Quanto à análise do texto da lei, foram elencados quesitos que versam sobre atribuições a serem cumpridas pelos organismos gestores da mobilidade urbana. Esses dois grupos de critérios foram reunidos para formar a matriz de avaliação;

2. Pesquisa documental e entrevistas in loco: publicações acadêmicas, leis estaduais e documentos institucionais do órgão gestor de transportes da Região Metropolitana de Recife foram utilizados para levantar informações sobre ele. Para confirmação dessas informações, foram realizadas entrevistas com dois diretores (André Melibeu e Alfredo Bandeira) e uma técnica administrativa do órgão (Ivana Vanderley), além de dois pesquisadores acadêmicos (Leonardo Meira e Oswaldo Lima Neto) e um consultor na área de transportes (Germano Travassos) com notável saber sobre o caso. Os roteiros das entrevistas foram fundamentados na pesquisa documental e nos critérios de avaliação da matriz;

3. Análise das informações e caracterização da estrutura organizacional: foi empregada a análise de conteúdo para analisar as informações obtidas nas entrevistas e nos documentos institucionais do órgão, com o intuito de descrever e interpretar o conteúdo de toda classe de documentos e textos. Segundo Moraes (1999), o processo de análise de conteúdo é constituído de cinco etapas, as quais foram desenvolvidas nesta pesquisa: preparação das informaç̧̃es, unitarização ou transformação do conteúdo em unidades, categorização ou classificação das unidades em categorias, descrição e interpretação (ver Moraes, 1999 para explicações detalhadas sobre cada etapa);

4. Avaliação da estrutura organizacional: a partir das informações analisadas na etapa anterior, a matriz avaliou a estrutura organizacional do órgão pesquisado com base na adequação aos requerimentos da Lei no 12.587/2012, em quais aspectos atendem e em quais não atendem à lei, justificando cada afirmação.

\section{A experiência do órgão gestor de mobilidade urbana da Região Metropolitana do Recife}

A Região Metropolitana do Recife (RMR) (Figura 1) está localizada no Estado de Pernambuco, o sétimo mais populoso do Brasil, na faixa litorânea e faz limite com municípios da Mesorregião da Mata do Estado. É a região metropolitana mais populosa da região Nordeste e a quinta do país, formada dos municípios: Abreu e Lima, Araçoiaba, Camaragibe, Cabo de Santo Agostinho, Goiana, Igarassu, Ilha de Itamaracá, Ipojuca, Itapissuma, Jaboatão dos Guararapes, Moreno, Olinda, Paulista, Recife e São Lourenço da Mata. 


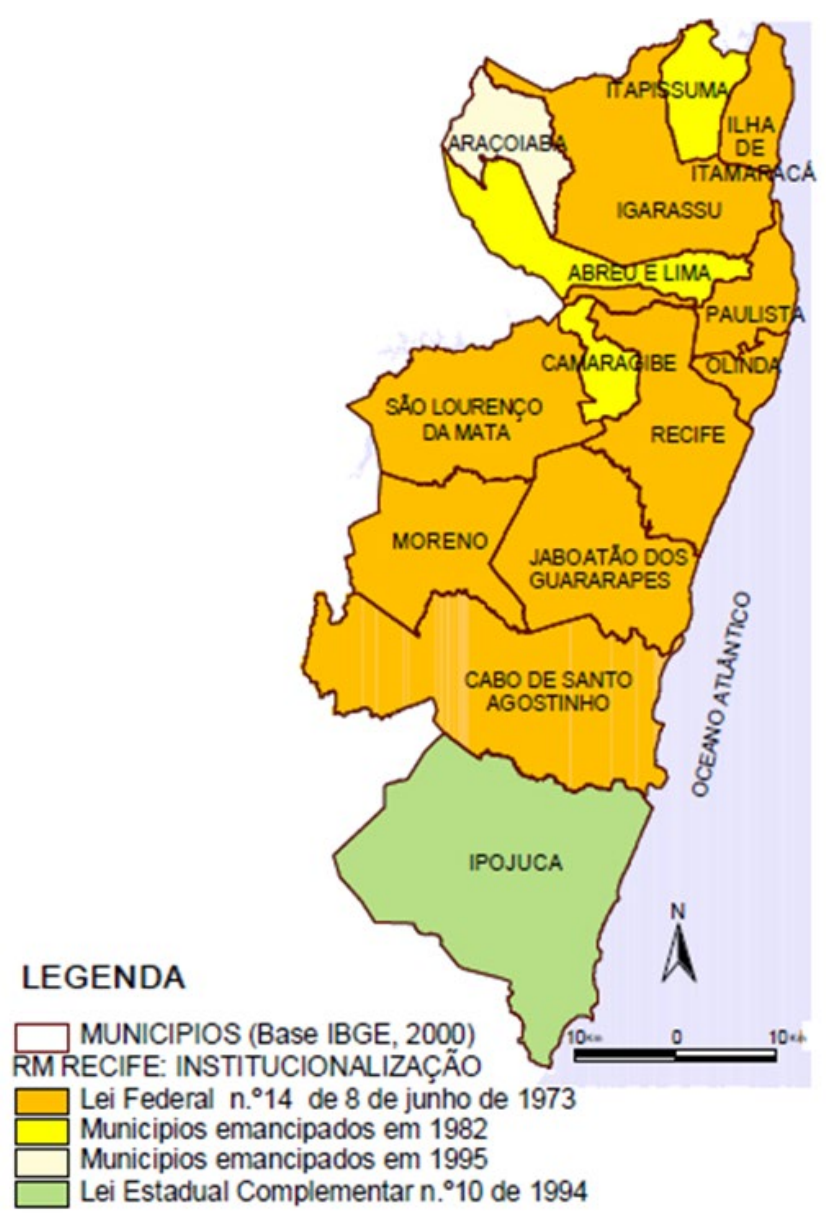

Figura 1 - Composição da Região Metropolitana do Recife destacando as fronteiras municipais e a sua evolução institucional. Fonte: CONDEPE/FIDEM (2006 apud Observatório das Metrópoles, 2010).

A RMR é densamente povoada, com população de 3.690 .547 habitantes, e reúne $42 \%$ da população total do Estado em uma área de $2.770 \mathrm{~km}^{2}$ (2,82\% do território estadual). A maior parte da população está concentrada na capital, Recife, com $41,6 \%$ dos habitantes. A RMR é majoritariamente urbana, com taxa de urbanização de 97,3\% (IBGE, 2010).

O órgão gestor de transportes na RMR é o Consórcio de Transportes da Região Metropolitana do Recife (CTM), cujo nome fantasia é Grande Recife, sediada na capital. A organização é um consórcio público, constituído pelo Estado de Pernambuco e os municípios metropolitanos de Olinda e Recife, formalizado pela Lei Estadual no 13.235, de 24 de maio de 2007, que ratifica o Protocolo de Intenções celebrado entre os entes consorciados.

O CTM foi a primeira experiência no país de consórcio público para transporte urbano criado nos termos da Lei Federal no 11.107, de 6 de abril de 2005 - a Lei de Consórcios Públicos. Inaugurado em 8 de setembro de 2008, atua como órgão gestor do Sistema de Transporte Público Coletivo de Passageiros da Região Metropolitana do Recife (STPP/RMR) e desenvolve todas as atividades de gestão do sistema, tais como: planejamento, programação das linhas, outorga dos serviços a terceiros por meio de licitação, gerência dos contratos de concessão e permissão, fiscalização dos serviços de transportes e avaliação dos operadores.

É importante fazer um breve histórico sobre o referido órgão. 0 CTM foi fundado a partir da Empresa Metropolitana de Transporte Público de Recife (EMTU/Recife), empresa pública estadual criada em 1979 no âmbito do Sistema Nacional de Transportes Urbanos (SNTU) - uma estrutura institucional relevante e uma das primeiras iniciativas estatais para enfrentar a problemática do transporte urbano nas cidades brasileiras nos anos 1970. Apesar de ter logrado êxito durante sua atuação, problemas de níveis de 
serviço e defasagem do modelo de gestão do transporte público centralizado no ente estadual levaram à substituição da empresa por uma nova estrutura de gestão compartilhada.

A estrutura institucional do CTM é formada por um arranjo que envolve instituições governamentais, legislações, agentes reguladores e fiscalizadores, além de operadores dos serviços de transportes (Ramalho, 2009).

A Figura 2 ilustra a estrutura institucional do CTM.

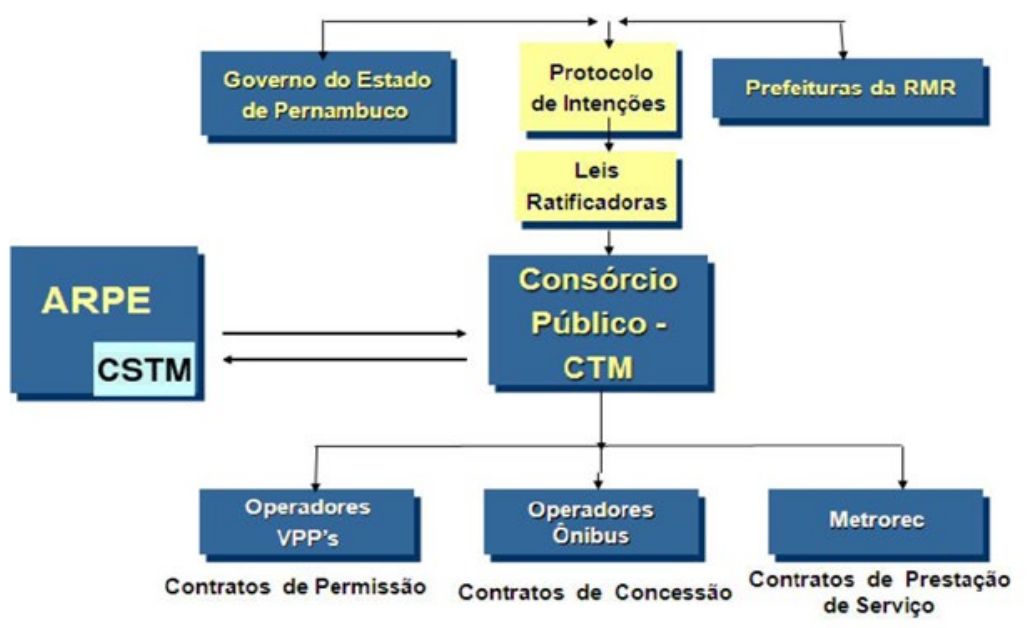

Figura 2 - Estrutura institucional do CTM. Fonte: Grande Recife (2008 apud Ramalho, 2009).

A estrutura institucional apresenta os entes consorciados: Governo do Estado de Pernambuco e prefeituras dos municípios metropolitanos. 0 Protocolo de Intenções estabelece a divisão das quotas em porcentagem no Consórcio para cada um dos municípios da RMR, designadas a partir do número de viagens geradas no STPP/RMR, com base nos dados da pesquisa domiciliar de origem/destino realizada na RMR em 1997. As quotas representam a parcela de poder decisório, ônus e ganhos do ente na prestação dos serviços.

Para aderir formalmente ao Consórcio, os entes devem aprovar leis ratificadoras. Até o momento desta pesquisa, apenas o Estado de Pernambuco e os municípios de Recife e Olinda aderiram ao Consórcio. Também faz parte da estrutura o Conselho Superior de Transporte Metropolitano (CSTM), órgão colegiado do CTM que deveria funcionar na estrutura organizacional da Agência de Regulação dos Serviços Públicos Delegados do Estado de Pernambuco (ARPE), mas isso não ocorre. A ARPE apenas participa como membro do Conselho. O CSTM é formado por representantes dos Poderes Executivo e Legislativo dos entes consorciados, dos sindicatos dos operadores e dos usuários.

$\mathrm{Na}$ base da estrutura estão os operadores de transportes do STTP/RMR, divididos em três categorias: operadores de veículos de pequeno porte (VPPs), que operam o serviço de transporte por vans e micro-ônibus com contrato de permissão; operadores de ônibus, cujo contrato é de concessão; e o Metrô de Recife (Metrorec), gerenciado e operado pela Companhia Brasileira de Trens Urbanos (CBTU) a partir de um contrato de prestação de serviços.

Durante a pesquisa empírica, os entrevistados relataram que a estrutura institucional elaborada na criação do Consórcio era a ideal, porém não existia na prática. 0 modelo inicialmente criado para o CTM era de uma sociedade por ações, na qual cada município deveria comprar suas quotas da maneira que estava designada no Protocolo de Intenções. No entanto, dos municípios metropolitanos, somente Olinda e Recife aderiram formalmente ao Consórcio, mas, na prática, apenas delegaram a gestão do sistema de transportes local e não assumiram a responsabilidade por suas quotas. Assim, o Consórcio é totalmente de responsabilidade do Estado de Pernambuco e, portanto, continua sendo tão estadual quando era a EMTU/Recife (Bandeira, 2015).

Sobre a adesão dos demais municípios da RMR ao Consórcio, diretores do órgão relataram que o interesse já foi maior. A adesão envolve uma questão técnica e política. É necessário que a rede interna 
de transportes seja reestruturada e que o transporte clandestino, que existe em grande quantidade na RMR, seja eliminado. Isso não é algo fácil de ser resolvido e envolve uma questão política, visto que alguns governantes não empenham esforços em alterar o sistema atual para não se indispor com os operadores e, assim, segurar votos nas eleições (Melibeu, 2015). Além disso, quando de partidos diferentes ao do governador do Estado, os prefeitos não querem negociar a entrada do município no Consórcio. Outra questão apontada foi o fato de que havia municípios com parcela de quota tão pequena que não se interessavam em aderir ao Consórcio, pois o poder de opinar e decidir sobre os serviços era quase nulo (Travassos, 2015).

Atualmente, apenas o município de Jaboatão dos Guararapes apresenta uma perspectiva real de aderir ao Consórcio, por possuir uma rede interna de transporte municipal por VPPs, e o CTM fez estudos para estruturá-la técnica e financeiramente. É necessário que haja uma racionalização da rede de transportes, diminuindo o número de permissionários, e que as linhas sejam delegadas ao Consórcio que se encarregará de realizar a licitação (Melibeu, 2015).

A licitação do STPP/RMR foi realizada em 2016, mas não para todo o sistema, apenas alguns lotes de ônibus. Com a CBTU, que opera os transportes por trilhos, não há contrato de prestação de serviços. Há um convênio para integração da tarifa no Sistema Estrutural Integrado (SEI). O CSTM não realiza reuniões com os seus membros periodicamente como deveria por seu caráter consultivo e deliberativo.

O CTM não exerce nenhuma relação de integração de planejamento com as prefeituras dos municípios não consorciados, entretanto o órgão continua operando as linhas metropolitanas nesses municípios. Da mesma forma, não exerce esse tipo de relação com os demais órgãos relacionados à questão da mobilidade urbana na RMR, dos quais fazem parte o órgão de transporte urbano por trilhos, os serviços de trânsito, as secretarias de serviços urbanos e o órgão estadual que trata da gestão metropolitana da RMR.

Como modos de transportes no STPP/RMR, o CTM gerencia os ônibus das linhas do SEI nas modalidades convencional, BRT (sigla em inglês de ônibus de trânsito rápido), BRS (ônibus de serviço rápido) e duas linhas metropolitanas de VPPs (micro-ônibus). 0 metrô, o trem e o VLT (veículo leve sobre trilhos), que também integram o SEI, são gerenciados pela CBTU. O SEI, por sua vez, é o desenho da rede metropolitana de transportes da RMR que foi criado em 1985 e posteriormente revisado em 1994 e em 2008. A rede de transportes é composta de dois sistemas: o SEI e o Sistema Complementar.

O Consórcio deverá gerir o transporte público por navegação fluvial (embarcações), mas a proposta ainda está em análise. 0 órgão não gerencia os transportes não motorizados, mas nos últimos anos desenvolveu algumas ações simples de incentivo à integração, como a implementação de bicicletários nas estações de BRT e em alguns terminais de integração e de passeios públicos nas estações de BRT.

Apesar de não estarem todos os municípios da RMR consorciados, os serviços de transportes gerenciados pelo CTM abrangem todos eles. Em Recife e Olinda, membros do Consórcio têm competência para gerenciar as linhas internas e intermunicipais, e nos demais municípios, apenas as linhas metropolitanas. Nestes últimos, os ônibus das linhas radiais do SEI trafegam nos corredores estruturais transportando passageiros dos municípios da RMR até o centro do Recife, mas não circulam fazendo deslocamentos internos. Há críticas quanto ao atendimento dos serviços do Consórcio nesses municípios, por exemplo, em Ipojuca não há terminal de ônibus do Consórcio (Meira, 2015).

\section{Avaliação da estrutura organizacional do órgão gestor de transportes da Região Metropolitana do Recife (RMR)}

Na avaliação da estrutura organizacional do órgão gestor de transportes da Região Metropolitana de Recife (RMR) - o CTM -, os itens elencados na matriz foram classificados em dois subgrupos: aspectos organizacionais oriundos da literatura de 0\&M e aqueles provenientes da Lei Federal no 12.587/2012. A avaliação dos aspectos organizacionais compreende os itens: histórico da organização, funções 
administrativas, elementos organizacionais formalizados, tecnologia da informação e comunicação (TICs) e ambiente organizacional.

O CTM, que tem 11 anos de existência, foi criado por lei em 2007. No entanto, originou-se da EMTU/Recife, fundada em 1979; assim, possui ampla cultura gerencial em transporte público desenvolvida ao longo dos anos.

O Consórcio prevê uma mudança no formato jurídico e na responsabilidade administrativa e financeira dos entes consorciados, mas até o momento presente não se consolidou. Foi apontado nas entrevistas que a organização apenas mudou de nome e continua com as mesmas práticas da antiga EMTU/Recife e ainda não evoluiu como consórcio público. Não adquiriu as práticas gerenciais específicas desse tipo de organização, como a gestão compartilhada dos serviços entre os entes consorciados e continua a operar como uma empresa pública à qual os municípios delegam suas atribuições setoriais. Contudo, considerando somente o período de existência como consórcio, na gestão interna a organização evoluiu quanto à estrutura organizacional, à gestão dos serviços e à qualificação do corpo técnico.

Recentemente foram criadas novas diretorias para tratar de assuntos relevantes ao desenvolvimento dos serviços de transporte público e que contribuem para o atendimento da Lei Federal no $12.587 / 2012$, por exemplo, a Diretoria de Projetos Especiais, criada em 2015 para gerenciar projetos complexos, como a implementação do BRT. O CTM possui servidores bem qualificados na área de transportes ou que estão se qualificando. Entretanto, é um corpo técnico "envelhecido", e muitos estão se aposentando, estando, assim, potencialmente desfalcado.

Para a gestão estratégica do órgão, foi formalizado o planejamento estratégico com visão, missão, objetivos e estratégias para a organização e para o STPP/RMR em concordância com as disposições da Lei Federal no 12.587/2012. De acordo com o mapa estratégico mais recente (período de 2012-2015), a visão organizacional seria consolidar o modelo de gestão consorciada até 2015. A missão é "[...] garantir a todos o acesso ao transporte público na Região Metropolitana do Recife, contribuindo para a melhoria da qualidade de vida". Também estão designados os objetivos organizacionais e para cada um desses programas e projetos que são as estratégias para alcançá-los. Alguns desses projetos estão em andamento e outros já foram realizados, por exemplo, a atualização do regulamento e do manual de operação do STTP/RMR.

A respeito do uso de TICs, conforme a lei, são infraestruturas da mobilidade urbana para controle, fiscalização, arrecadação de taxas e tarifas e difusão de informações (Art. 3oㅗ $\S 3$, inciso VII). Estão presentes no órgão um plano de TI, a bilhetagem eletrônica, uma central de controle de operação e um sistema integrado de controle da mobilidade que está em implantação.

São vários atores envolvidos na questão da mobilidade urbana em âmbito metropolitano. Para uma gestão eficaz, é necessário levar em consideração a articulação entre esses atores. Apesar de o CTM ser uma empresa pública do Estado de Pernambuco, foi apontado nas entrevistas que não havia relacionamento institucional com a agência reguladora de serviços públicos do Estado (ARPE). Mesmo com sua função, o órgão não fiscaliza os serviços do CTM e formalmente possui representação no CSTM, mas na prática não há relacionamento entre os dois órgãos desde a criação do Consórcio.

No que cabe ao relacionamento com os órgãos municipais de transportes e trânsito, nos municípios consorciados o CTM assume a competência da gestão do transporte coletivo, e a do trânsito está sob responsabilidade de outros órgãos municipais. Em Recife, o órgão responsável pela gestão de trânsito, Autarquia de Trânsito e Transporte de Recife (CTTU), também gerencia algumas linhas internas de VPPs e os demais modos de transporte urbano na cidade, porém não há relacionamento entre os dois órgãos para o planejamento e integração das linhas gerenciadas por eles.

Nos municípios não consorciados, há órgãos que realizam a gestão de trânsito e transportes de suas linhas internas. De modo geral, foi constatado que não há nenhum relacionamento institucional em termos de planejamento entre o CTM e os órgãos citados; o que ocorre são relações pontuais quando necessárias em termos de serviços. Por vezes a relação com esses órgãos recebe influência de divergências políticas entre o governo estadual e os municípios, o que prejudica a efetividade dos serviços de transportes para a população. 
No tocante ao relacionamento com o órgão gestor do transporte ferroviário na RMR - a CBTU -, existe entre os órgãos um convênio de cooperação técnica em que alguns servidores da CBTU estão cedidos ao CTM. Também há um convênio para integração física dos usuários nos terminais de integração do SEI e não tarifária, haja vista que a tarifa do ônibus é superior à tarifa do metrô. Não há relacionamento institucional em termos de planejamento dos serviços de transportes e tampouco diálogo entre os órgãos para a alocação dos serviços. Tal relacionamento poderia melhorar a oferta dos serviços do STTP/RMR, se fossem consideradas as necessidades da população. Em termos práticos, seria alocar a oferta do transporte coletivo rodoviário ou ferroviário considerando a melhor condição de acesso e mobilidade à população. Seria uma relação de planejamento entre as instituições para a complementariedade dos serviços, diferentemente da relação de competição que existe agora.

Quanto ao relacionamento do órgão com as empresas operadoras de transporte coletivo, foi realizada a licitação em 2016, mas até o momento desta pesquisa somente dois contratos haviam sido assinados. O certame já conta com o regulamento do STPP/RMR e o manual de operação do STPP/RMR atualizados, com as normas estabelecidas para a operação dos serviços, o que revela que o órgão está evoluindo para adequar-se à referida lei nesse sentido.

A avaliação dos aspectos elencados da Lei Federal no 12.587/2012 considerou os itens: modos de transportes gerenciados, integração nos transportes, informações do transporte coletivo, comunicação e informação ao usuário, elementos de gestão participativa, infraestruturas de mobilidade urbana, gestão do trânsito, capacitação de pessoas em mobilidade urbana, políticas de sustentabilidade ambiental para os transportes, acessibilidade, transparência, integração com as políticas setoriais urbanas e Plano de Mobilidade Urbana.

O CTM realiza a gestão completa do modo de transporte coletivo por ônibus no SEI, realizando o planejamento, a contratação dos serviços, a gestão de contratos e a fiscalização. Por isso estão cumprindo a lei, com base nos Artigos 17 e 18, embora de forma parcial, pois ela coloca que os órgãos gestores devem planejar e coordenar os diferentes modos e serviços de mobilidade urbana (Art. 22, I), e não apenas o transporte coletivo. Além disso, o CTM não desenvolve relação de planejamento com os órgãos gestores dos demais modos de transportes.

Foi avaliado se o órgão prevê em suas atribuições e responsabilidades a integração intramodal e intermodal. Entre os princípios da PNMU consta a integração entre os modos e serviços de transporte

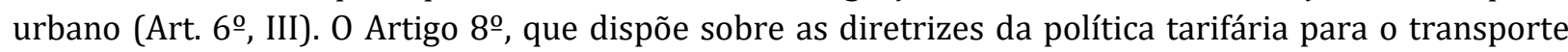
coletivo, ressalta a "[...] integração física, tarifária e operacional dos diferentes modos e das redes de transporte público e privado nas cidades" (Art. 8ํ, VII). E, no Artigo 17, como atribuição dos Estados, está promover a integração dos serviços de transportes nas áreas que ultrapassem os limites de um município. O CTM realiza integração física ônibus-ônibus e ônibus-metrô intramunicipal somente em Recife e Olinda, e intermunicipal nos demais municípios da RMR nas linhas metropolitanas dos terminais do SEI. Em Recife, a integração ocorre somente entre as linhas do SEI, e não com as linhas de VPPs gerenciadas por um órgão municipal. O CTM não prevê integração com outros modos de transportes. Assim, considera-se que ele atende parcialmente à lei, mas que ainda há muito a evoluir nesse importante quesito.

A PNMU dispõe sobre os direitos dos usuários como: “[...] ser informado nos pontos de embarque e desembarque de passageiros, de forma gratuita e acessível, sobre itinerários, horários, tarifas dos serviços e modos de interação com outros modais" (Art. 14, III). Estão disponíveis todas essas informações não só nos pontos de embarque e desembarque, mas também nos meios de comunicação disponibilizados pelo órgão, tais como o canal de atendimento ao usuário e o site institucional com informações relevantes sobre as linhas de ônibus.

É atribuição dos órgãos de mobilidade urbana, de acordo com a Lei no 12.587/2012, dispor sobre sistemas de avaliação de desempenho e qualidade dos serviços (Art. 22, II). 0 manual de operação do STPP/RMR estabelece medidas de avaliação de desempenho e penalidades para as empresas operadoras.

As infraestruturas de mobilidade urbana compõem o sistema (Art. $3^{\circ}$ o $§ 3$ ) e, portanto, são importantes para a consolidação da PNMU. 0 órgão é responsável pela manutenção das infraestruturas e pequenas 
obras nos terminais e paradas de ônibus. A construção de obras de grande vulto é de competência da secretaria estadual, à qual o CTM está vinculado, e na estrutura organizacional do órgão existe a Diretoria de Projetos Especiais, que acompanha os projetos executados por essa secretaria.

Conclui-se que, para o transporte coletivo por ônibus, o CTM atende aos requisitos da lei, mas não para os demais modos, pois não os gerencia e tampouco estabelece relacionamento institucional com os órgãos competentes.

0 trânsito é uma infraestrutura de mobilidade urbana (Art. $3, \S 3, \mathrm{~V}$ ), relevante ao bom funcionamento da função, porém o CTM é um órgão gestor apenas de transporte coletivo. É importante que exista integração no planejamento com os órgãos gestores de trânsito, e não foi verificada na pesquisa empírica atributos de tal relação. Também existe influência de divergências políticas entre os órgãos competentes. Dessa maneira, para tal, o CTM não atende à Lei no $12.587 / 2012$.

Outro ponto importante ressalvado pela lei é a capacitação continuada de pessoas em mobilidade urbana como atribuição da União e dos municípios (Art. 16 e 18). 0 CTM é um órgão de gestão metropolitana de transportes e que também atua como órgão municipal nos municípios consorciados. Nesse quesito, foi considerada a capacitação dos operadores, que não é realizada diretamente pelo órgão, mas é exigida formalmente no manual de operação do sistema, pois as empresas devem prover capacitação para seus funcionários.

A gestão democrática do sistema de mobilidade urbana é um dos meios para a concretização dos

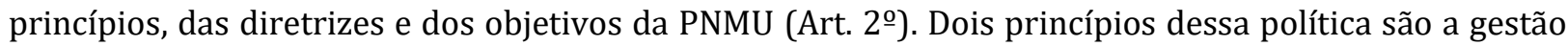
democrática e o controle social do planejamento e avaliação da PNMU (Art. 5o, V). Um dos objetivos é "[...] consolidar a gestão democrática como instrumento e garantia da construção contínua do aprimoramento da mobilidade urbana" (Art. 7ำ, V). 0 Artigo 15 preceitua que a participação da sociedade civil no planejamento, na fiscalização e na avaliação da PNMU deverá ser assegurada pela gestão participativa. Portanto, foi avaliado se estão previstos no órgão instrumentos de gestão participativa, tais como: ouvidoria, órgãos colegiados, consultas e auditorias públicas. Esses elementos estão previstos, exceto as consultas públicas. Embora não haja consultas públicas periodicamente, há disponibilidade ao atendimento de representantes de comunidades que se dirigem ao órgão, segundo apontado pelos diretores do órgão nas entrevistas. As auditorias públicas são realizadas para ouvir a população sobre obras de grande vulto financeiro, como requer a Lei no 8.666/1993 de licitações e contratos. Nesse sentido, formalmente o órgão atende às determinações da Lei Federal no $12.587 / 2012$, embora não se descarte a importância das consultas públicas.

A simplicidade na compreensão, na transparência da estrutura tarifária para o usuário e na publicidade do processo de revisão (Art. 8, V) é uma das diretrizes para regulação do transporte coletivo. O CTM divulga informações de transparência conforme prevê a Lei de Acesso à Informação (LAI), mas não de maneira clara e simples ao usuário sobre a tarifa, como prevê a política.

A PNMU tem como um de seus objetivos promover o desenvolvimento sustentável com a mitigação de custos ambientais nos deslocamentos de pessoas e cargas nas cidades (Art. 7으, IV). Como medidas para alcance estão o incentivo aos transportes coletivos e aos não motorizados, o uso de energias renováveis e o controle de gases poluentes emitidos pelos transportes motorizados.

O CTM não dispõe de política de sustentabilidade ambiental direcionada aos transportes. Realiza o controle de emissão de gases poluentes nos veículos da frota, requerido pelas normas Euro de poluentes e previsto no manual de operação do STPP/RMR como um dos índices de adequabilidade do serviço prestado. As demais medidas citadas não ocorrem ou são incipientes, não tendo uma previsão formal ou não podendo ser avaliadas nesse contexto. Na estrutura organizacional, existe uma coordenadoria responsável por tratar de impactos ambientais, mas não foi citada durante as entrevistas. Avalia-se que o órgão está parcialmente adequado à referida lei nessa questão.

A acessibilidade universal é um dos princípios da PNMU e um dos objetivos é "[...] proporcionar melhoria nas condições urbanas da população no que se refere à acessibilidade e à mobilidade" (Art. $7^{\circ}$ III). Foi questionado se há política ou atribuições voltadas à acessibilidade universal dos usuários ao transporte público e às infraestruturas que o servem. 0 órgão busca atender às normas técnicas exigidas para projetos arquitetônicos e veículos. As obras mais recentes seguem os padrões de 
acessibilidade, porém as antigas continuam sem atendê-los; deveria ocorrer a conversão, mas não constam atribuições para isso. Assim, estão parcialmente alinhados à Lei Federal no 12.587/2012.

Como diretriz, a PNMU estabelece a integração da política de mobilidade com a política de desenvolvimento urbano e as respectivas políticas setoriais de habitação, saneamento básico, planejamento e gestão do uso do solo no âmbito dos entes federativos (Art. 6으, I). Foi relatado nas entrevistas que o CTM não desenvolve nenhuma relação para integração de planejamento entre essas políticas. Apenas acontecem medidas pontuais por meio de ordens de serviço, quando a prestação de um serviço necessita de outro relativo aos órgãos setoriais. Portanto, para tal critério não atende à lei.

Referentes aos critérios de sustentabilidade ambiental, acessibilidade e integração com as políticas setoriais urbanas, foi observado que as atribuições do órgão ainda são incipientes, pois elas deveriam ser tratadas pelo órgão em termos de política pública e disseminadas como atribuições, e não em medidas pontuais ou eventuais.

O Plano de Mobilidade Urbana (Plamob) é o instrumento de efetivação da PNMU no município. Desse modo, é importante que os municípios estabeleçam Plamob atualizados com a Lei Federal no 12.587/2012 e que estejam internalizados nas atribuições do órgão. A importância desse instrumento é dada não só pelas suas diretrizes de planejamento, mas também pelo fato de que, se não for elaborado no prazo de sete anos a partir da data de promulgação da lei, o município ficará impedido de receber recursos federais destinados à mobilidade urbana até que seja elaborado (Art. 24, § 6으).

O CTM é um órgão metropolitano, portanto é adequado que esteja alinhado a um plano metropolitano de mobilidade urbana, que também ainda não existe na RMR atualizado às Leis Federais no 12.587/2012 e no 13.089/2015 (Estatuto da Metrópole). Existe o Plano Diretor de Transporte Urbano da RMR de 2008, que, no momento das entrevistas, não estava em processo de atualização às referidas leis. 0 CTM também atua como órgão municipal de transporte público em Recife e Olinda e deve estar alinhado ao Plamob desses municípios - planos que estão em processo de elaboração. Não há uma política local ou metropolitana de mobilidade urbana baseada na Lei Federal ํㅜ 12.587/2012 internalizada pelo órgão. Assim, nesse quesito, o órgão não atende às determinações dessa lei. A Tabela 3 apresenta um resumo dos principais resultados da avaliação realizada pelo método da pesquisa a partir das informações levantadas nas entrevistas e nos documentos institucionais do órgão gestor.

Tabela 3 - Avaliação da estrutura organizacional do CTM diante dos requisitos da Lei n 12.587/2012

\begin{tabular}{|c|c|c|c|c|c|}
\hline & \multirow{2}{*}{ Critérios } & \multicolumn{3}{|c|}{ Adequação à Lei nº 12.587/2012 } & \multirow{2}{*}{ Justificativa } \\
\hline & & Sim & Não & Parcial & \\
\hline \multirow{5}{*}{ 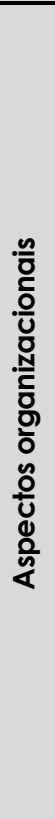 } & $\begin{array}{l}\text { Histórico da } \\
\text { organização }\end{array}$ & & & $x$ & $\begin{array}{c}\text { Possui ampla cultura em transporte público, } \\
\text { com corpo técnico qualificado, evoluiu na } \\
\text { estrutura organizacional ao longo dos anos, } \\
\text { mas não amadureceu como consórcio } \\
\text { público. }\end{array}$ \\
\hline & $\begin{array}{c}\text { Funções } \\
\text { organizacionais }\end{array}$ & $x$ & & & $\begin{array}{c}\text { As funções do processo administrativo } \\
\text { (planejamento, organização, direção e } \\
\text { controle) estão previstas para a gerência do } \\
\text { transporte coletivo. }\end{array}$ \\
\hline & $\begin{array}{l}\text { Planejamento } \\
\text { estratégico }\end{array}$ & $x$ & & & $\begin{array}{c}\text { Possui planejamento estratégico formalizado } \\
\text { com os elementos visão, missão, objetivos } \\
\text { organizacionais, metas e estratégias } \\
\text { organizacionais. }\end{array}$ \\
\hline & $\begin{array}{l}\text { Uso da tecnologia da } \\
\text { informação }\end{array}$ & $x$ & & & $\begin{array}{c}\text { Dispõe de Plano de Tl, bilhetagem eletrônica, } \\
\text { central de controle de operação; está em } \\
\text { implantação o sistema integrado de controle } \\
\text { da mobilidade. }\end{array}$ \\
\hline & $\begin{array}{c}\text { Ambiente } \\
\text { organizacional }\end{array}$ & & $x$ & & $\begin{array}{l}\text { Apesar de possuir uma estrutura organizacional } \\
\text { madura, no ambiente externo apresenta-se } \\
\text { como um órgão "fechado", de pouco } \\
\text { relacionamento com organizações importantes } \\
\text { envolvidas na mobilidade na RMR. }\end{array}$ \\
\hline
\end{tabular}


Tabela 3 - Continuacão...

Avaliação das estruturas organizacionais dos organismos gestores da mobilidade diante da Política Nacional de Mobilidade Urbana

\begin{tabular}{|c|c|c|c|c|c|}
\hline & \multirow{2}{*}{ Critérios } & \multicolumn{3}{|c|}{ Adequação à Lei nº 12.587/2012 } & \multirow{2}{*}{ Justificativa } \\
\hline & & Sim & Não & Parcial & \\
\hline \multirow{14}{*}{ 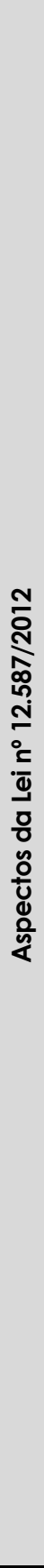 } & $\begin{array}{l}\text { Modos de transportes } \\
\text { gerenciados }\end{array}$ & & & $x$ & $\begin{array}{c}\text { Somente o transporte coletivo por ônibus que } \\
\text { opera nas linhas do SEl. }\end{array}$ \\
\hline & $\begin{array}{l}\text { Integração nos } \\
\text { transportes }\end{array}$ & & & $X$ & $\begin{array}{c}\text { Ocorre integração intramunicipal e } \\
\text { metropolitana ônibus-ônibus e ônibus-metrô, } \\
\text { ambas no SEl. }\end{array}$ \\
\hline & $\begin{array}{l}\text { Infraestruturas de } \\
\text { mobilidade urbana }\end{array}$ & $x$ & & & $\begin{array}{l}\text { São de competência do órgão os corredores } \\
\text { de BRT, os passeios públicos ao entorno, os } \\
\text { serviços de manutenção e pequenas obras } \\
\text { nos terminais e a locação e relocação de } \\
\text { paradas e pontos de ônibus. }\end{array}$ \\
\hline & $\begin{array}{l}\text { Avaliação de } \\
\text { desempenho nos } \\
\text { serviços }\end{array}$ & $x$ & & & $\begin{array}{l}\text { Há padrões de avaliação formalmente } \\
\text { previstos no manual de operação do sistema. }\end{array}$ \\
\hline & Gestão do trânsito & & $x$ & & $\begin{array}{c}\text { Não competem ao órgão as atividades da } \\
\text { gestão de trânsito. }\end{array}$ \\
\hline & $\begin{array}{l}\text { Capacitação de } \\
\text { pessoas em } \\
\text { mobilidade urbana }\end{array}$ & $x$ & & & $\begin{array}{l}\text { Não é realizada diretamente pelo órgão, mas } \\
\text { é formalmente exigido que seja realizada. }\end{array}$ \\
\hline & $\begin{array}{c}\text { Medidas de } \\
\text { sustentabilidade } \\
\text { ambiental }\end{array}$ & & & $x$ & $\begin{array}{l}\text { Os veículos da frota estão adequados às } \\
\text { normas EURO } 5 \text { de controle de emissão de } \\
\text { poluentes. }\end{array}$ \\
\hline & $\begin{array}{l}\text { Comunicação e } \\
\text { informação ao usuário }\end{array}$ & $x$ & & & $\begin{array}{c}\text { Existe um canal } 0800 \text { de atendimento ao } \\
\text { usuário, mídias impressas (placas) nas } \\
\text { estações de ônibus e informações relevantes } \\
\text { no site do órgão. }\end{array}$ \\
\hline & $\begin{array}{l}\text { Informações do } \\
\text { transporte coletivo }\end{array}$ & $x$ & & & $\begin{array}{l}\text { Informações sobre tarifas, horários e itinerários } \\
\text { estão disponíveis nos meios de comunicação } \\
\text { previstos pelo órgão. }\end{array}$ \\
\hline & $\begin{array}{l}\text { Instrumentos de } \\
\text { gestão participativa }\end{array}$ & $x$ & & & $\begin{array}{c}\text { Formalmente dispõe de ouvidoria e órgão } \\
\text { colegiado em sua estrutura. Ocasionalmente } \\
\text { ocorrem consultas públicas e auditorias } \\
\text { públicas (para projetos de grande vulto } \\
\text { financeiro). }\end{array}$ \\
\hline & Acessibilidade & & $x$ & & $\begin{array}{l}\text { O órgão busca atender às normas técnicas } \\
\text { exigidas para as infraestruturas e os veículos. } \\
\text { No entanto, não há atribuições para } \\
\text { adequação das infraestruturas antigas. }\end{array}$ \\
\hline & $\begin{array}{c}\text { Integração com as } \\
\text { políticas setoriais } \\
\text { urbanas }\end{array}$ & & $x$ & & $\begin{array}{l}\text { Não há planejamento integrado entre o } \\
\text { órgão de transporte e os órgãos responsáveis } \\
\text { por essas políticas. }\end{array}$ \\
\hline & $\begin{array}{l}\text { Transparência e } \\
\text { simplicidade na tarifa }\end{array}$ & & $x$ & & $\begin{array}{c}\text { No site institucional, constam informações de } \\
\text { transparência do órgão, mas não foi } \\
\text { verificada a previsão quanto à tarifa da } \\
\text { maneira que requer a lei. }\end{array}$ \\
\hline & $\begin{array}{l}\text { Plano de Mobilidade } \\
\text { Urbana }\end{array}$ & & $x$ & & $\begin{array}{l}\text { Não há Plamob elaborado nos municípios } \\
\text { consorciados e com atribuições internalizadas } \\
\text { pelo órgão. }\end{array}$ \\
\hline
\end{tabular}

Fonte: Elaborada pelos autores (2016).

\section{Considerações finais}

A pesquisa avaliou a estrutura organizacional do órgão de gestão de transportes na Região Metropolitana de Recife (RMR), o Consórcio de Transportes da Região Metropolitana do Recife (CTM). 0 método proposto, e também elaborado nesta pesquisa, foi a matriz de avaliação. Por meio dela foi possível sistematizar os aspectos mais relevantes para um órgão gestor de transportes adequar-se à Lei Federal no 12.587/2012. 
Além do diagnóstico de adequação à lei, a pesquisa permitiu identificar o contexto de gestão do órgão pesquisado. 0 CTM foi idealizado com uma modelagem para ter o formato jurídico de uma sociedade por ações, e os acionistas seriam os municípios da RMR e o governo estadual. Mas até o momento desta pesquisa, mesmo após nove anos de existência, possuindo vasta cultura em transporte urbano e um corpo técnico qualificado na área, apenas Recife, Olinda e o Estado de Pernambuco fazem parte do Consórcio. Na prática, continua sendo uma empresa pública estadual como era a EMTU/Recife.

A principal barreira para a consolidação plena do Consórcio está no fator político, nas divergências partidárias entre os governos municipais e estadual. Em segundo plano, está o desinteresse dos municípios menores na adesão, que possuem baixa porcentagem de cotas. Entretanto, o maior entrave para a participação dos municípios está no fato de que estes devem racionalizar a sua rede local de transportes, especialmente no que tange à inibição de serviços de transporte clandestino e alternativo. Isso não ocorre facilmente, pois há também um interesse político dos gestores desses municípios em assegurar votos. De modo geral, a consolidação do Consórcio é prejudicada por um embate político, e não técnico.

A consolidação do modelo consorcial é importante para que haja a melhoria da prestação dos serviços para os demais municípios da RMR, onde atualmente as queixas são frequentes. Por isso, este trabalho propõe a aproximação entre os municípios e o órgão por meio da efetiva atuação do órgão colegiado - o CSTM. A pesquisa constatou por meio das entrevistas que o CSTM não está funcionando efetivamente como órgão colegiado do Consórcio. Isso influencia para que não haja a concretização do modelo consorcial, que contribuiria para a efetivação da PNMU.

O CTM apresenta um caráter técnico gerencial e uma estrutura organizacional bem estabelecida para realizar os serviços que estão propostos, isto é, para a gestão do transporte coletivo. Mesmo assim, não está totalmente adequado do ponto de vista da Lei no $12.587 / 2012$, por não gerenciar outros modos de transportes e serviços da mobilidade urbana e não estabelecer relacionamento institucional formalizado e de caráter contínuo com os órgãos competentes. O CTM demostra ser um órgão "fechado" em relação ao ambiente externo, com órgãos metropolitanos locais de trânsito e transportes e do transporte ferroviário. Por outro lado, com as empresas operadoras apresenta relacionamento institucional formalizado, com tendência a melhorias após a licitação do sistema de transportes.

Quanto ao Plamob, em Recife ainda não há plano elaborado atualizado com a Lei no 12.587/2012, estando em processo de elaboração, mas o CTM não estava envolvido nesse processo. Por ser um órgão metropolitano, almeja a elaboração de um plano de transportes, o qual está em estudo, mas ainda não há nada concreto. No entanto, Recife é o destino da maior parte das viagens realizadas pelo Consórcio, por isso é importante existir mais proximidade do órgão nesse processo.

A pesquisa revelou que, apesar de o CTM ser bem estruturado e estar evoluindo para novas tecnologias, a PNMU está muito avançada, diante da capacidade potencial de ser implementada pelo órgão. Foi criado em anos anteriores, muito antes da PNMU, e, portanto, necessita de uma adequação de suas competências e da estrutura organizacional para atender à política. Quando de sua criação, vigorava o modelo de mobilidade urbana centrado no transporte de massa e na organização do tráfego. 0 novo conceito de mobilidade urbana que vem sendo difundido internacional e nacionalmente considera a mobilidade urbana como uma função mais ampla, que inclui no escopo o planejamento e a gestão de outros modos de transporte - ressaltam-se os não motorizados. A PNMU compreende esse conceito e busca desenvolvê-lo por meio de serviços, porém o órgão avaliado nesta pesquisa não está equipado para isso.

Nos locais onde o órgão avaliado atua, existe uma multiplicidade de organizações que desempenham serviços finalísticos para a mobilidade urbana ou executam serviços relacionados - algumas são de níveis de governo diferentes ao órgão gestor, apresentando conflitos causados por interesses políticos. Desse modo, há a indiscutível necessidade de haver entendimento entre as lideranças locais para que haja a efetivação da PNMU e melhoria dos serviços de mobilidade urbana.

Um órgão com uma estrutura organizacional bem estabelecida apresenta mais possibilidades para que os objetivos da organização sejam cumpridos satisfatoriamente. Assim, uma estrutura organizacional 
alinhada aos requisitos da PNMU possibilita que ela seja efetivada. Para isso, é necessário que ações sejam concretizadas. Mas o intuito deste trabalho é fazer com que os organismos de gestão da mobilidade urbana compreendam que não devem descuidar da estrutura organizacional, porque sem uma boa estrutura organizacional não existe eficiência nem eficácia na implementação da PNMU.

\section{Referências}

Bandeira, A. (2015, 28 de outubro). Entrevista concedida à Aramidis Cibelly Moura de Morais. Recife.

Bassul, J. R. (2002). Reforma urbana e Estatuto da Cidade. EURE, 28(84), 133-144.

Boareto, R. (2003). A mobilidade urbana sustentável. Revista dos Transportes Públicos, 25(3), 45-56.

Brasil. (1988, 5 de outubro). Constituição Federal da República do Brasil. Brasília: Diário Oficial da União.

Brasil. (2001, 11 de julho). Lei n. 10.257, de 10 de julho de 2001. Estabelece as diretrizes gerais da política urbana e dá outras providências. Brasília: Diário Oficial da União.

Brasil. (2012, 4 de janeiro). Lei n. 12.587, de 3 de janeiro de 2012. Estabelece as diretrizes para a Política Nacional de Mobilidade Urbana. Brasília: Diário Oficial União.

Brasil. Ministério das Cidades. (2015). PlanMob: caderno de referência para elaboração de plano de mobilidade urbana. Construindo a cidade sustentável. Brasília: Secretaria Nacional de Transporte e da Mobilidade Urbana.

Fernandes, E. (2010). 0 Estatuto da Cidade e a ordem jurídico-urbanística. In C. S. Carvalho, \& A. C. Rossbach (Eds.), O Estatuto da Cidade: comentado. São Paulo: Aliança das Cidades.

Gomide, A. A. (2007). 0 projeto de lei de diretrizes da política nacional de mobilidade urbana. Revista dos Transportes Públicos ANTP, 30(4), 77-93.

Instituto Brasileiro de Geografia e Estatística - IBGE. (2010). Censo demográfico: 2010. Rio de Janeiro: IBGE. Recuperado em 10 de abril de 2015, de www.ibge.gov.br

Instituto Brasileiro de Geografia e Estatística - IBGE. (2012). Pesquisa nacional por amostra de domicílios contínua: 2012. Rio de Janeiro: IBGE. Recuperado em 10 de abril de 2015, de www.ibge.gov.br

Instituto Brasileiro de Pesquisa Aplicada - IPEA. (2012). Comunicação no 128: a nova lei de diretrizes da Política Nacional de Mobilidade Urbana. Brasília: IPEA.

Lima, C., No. \& Galindo, E. P. (2013). A Política Nacional de Mobilidade Urbana, os Planos de Mobilidade e os municípios brasileiros. In Anais do XXVII Congresso de Pesquisa e Ensino em Transportes. Belém: ANPET.

Meira, L. (2015, 30 de outubro). Entrevista concedida à Aramidis Cibelly Moura de Morais. Recife.

Melibeu, A. (2015, 28 de outubro). Entrevista concedida à Aramidis Cibelly Moura de Morais. Recife.

Moraes, R. (1999). Análise de conteúdo. Review of Education, 22(37), 7-32.

Observatório das Metrópoles. (2010). Recuperado em 20 de abril de 2015, de www.observatoriodasmetropoles.net

Ramalho, A. M. F. (2009). Autonomia e cooperação: os desafios da gestão metropolitana (Tese de doutorado). Universidade Federal de Pernambuco, Recife.

Travassos, G. (2015, 29 de outubro). Entrevista concedida à Aramidis Cibelly Moura de Morais. Recife.

\section{Editor: Fábio Duarte}

Recebido: Ago. 22, 2019

Aprovado: Jan. 03, 2020 